\title{
EL TRATAMIENTO CON SULFAMETOXAZOL-TRIMETOPRIM DE LA BLENORRAGIA FEMENINA
}

\author{
C. B. S. SCHOFIELD \\ M. MOFFETT
}

G. MASTERTON

M. I. MCGILL

Departamento de Venereología del Hospital Ruchill, Glasgow, N. W.

El trimetoprim (2,4-diamino-5(31, 41,51-trimetoxibencil)-pirimidina), fue descrito por primera vez por Roth, Falco, Hitching y Bushby (1962). En las bacterias, es un poderoso inhibidor de la reductasa del ácido dihidrofólico en la fase de la síntesis del DNA, inmediatamente después de la bloqueada por la sulfamida. Por consiguiente, se comprende fácilmente el sinergismo entre estas dos sustancias antibacterianas y en la actualidad resulta posible curar infecciones producidas por organismos hasta ahora resistentes a las sulfamidas. Estas sustancias, asociadas, son bactericidas y a esto se debe, probablemente, la rápida mejora que frecuentemente se observa durante su empleo clínico (Darrell, Garrod y Waterworth, 1968). De la serie de microorganismos contra los que ha sido ensayado, el grado de potenciación más alto fue el alcanzado contra la N. gonorrhoea, sugiriendo también que el sulfametoxazol fue la mejor sulfamida para utilizar con el trimetoprim, ya que sus proporciones de presencia y desaparición de la sangre fueron similares cuando se administra por vía oral. Esto confirma los hallazgos de Csonka y de Knight
(1967), que trataron a una serie de pacientes masculinos que padecían blenorragia, con trimetoprim y diversas sulfamidas. La mayor proporción de curaciones, $93 \%$ (39 de 42), se consiguió entre aquellos enfermos a los que se administró un tratamiento de 4 días de sulfametoxazol con trimetoprim, (Bactrim) siendo la dosis diaria respectiva de 2.000 y 400 mg. Esta investigación se ocupa del tratamiento de la blenorragia en pacientes femeninos.

\section{Materiales y Métodos}

Seguimos ciertos criterios en cuanto a la selección y control de los pacientes femeninos a incluir en esta investigación:

(1) Fueron excluídas las embarazadas, las pacientes en que había fallado anteriormente el sistema y las que se esperaba que abandonaran la localidad en un período de un mes.

(2) El diagnóstico fué confirmado por el cultivo y el informe bacteriológico debía comprender un antibiograma completo, junto con la sensi- 
bilidad o resistencia al sulfametoxazol-trimetoprim.

(3) El tratamiento de repetición únicamente se llevó a cabo después de recibir informes sobre un cultivo positivo. En caso de fracaso se cambió el medicamento $y$, en reinfecciones, se repitió el sulfametoxazol/trimetoprim.

(4) En el examen inicial (día 1) se tomaron frotis y cultivos de la uretra y del cuello uterino, sangre para pruebas serológicas, destinadas a la comprobación de la sífilis, estimación de la hemoglobina, volumen celular y número total de leucocitos, en la forma rutinaria. Los frotis y cultivos se repitieron en cada visita, los días 3,4 ó 5 y en los días 8, 15, 22 y 29 , cuando se repitieron todas las comprobaciones sanguíneas.

(5) Dejaron de investigarse las pacientes cuando el fracaso fue completo, después del fallo del tratamiento, de reinfección o si se habían administrado antibióticos por otras causas.

(6) La dosis empleada en este estudio fue de 2 grageas de Bactrim, cada una de las cuales contenía 400 mg. de sulfametoxazol y $80 \mathrm{mg}$. de trimetoprim, noche y día y, preferiblemente, a intervalos de 12 horas, durante un total de 5 días.

\section{Resultados}

El 3 de Abril, se habían administrado 65 tratamientos a 64 pacientes, uno de los cuales fué repetido como consecuencia de una reinfección; pero el estudio continuará hasta los 100 tratamientos. Todas las pacientes habían nacido en el Reino Unido y su edad oscilaba entre 18 y 42 años, con una media de 25,7 años. Veintiseis eran casadas, 23 solteras, 11 separadas y 4 divorciadas. Seis tenían antecedentes de blenorragia y 2 , más de un contacto.

\section{TABLA 1}

RESISTENCIA DE 56 CEPAS DE N. GONORRHOEA A LA ESTREPTOMICINA Y AL SULFAFURAZOL POR SUS SENSIBILIDADES RELATIVAS A LA PENICILINA*

(En 9 cepas no se obtuvieron informes completos de los cultivos)

\begin{tabular}{|c|c|c|c|c|c|}
\hline \multirow[b]{2}{*}{$\underset{\mathrm{G}}{\mathrm{CIM}}$} & \multirow[b]{2}{*}{$\begin{array}{l}\text { de penicilina } \\
\text { en } \mathrm{ug} / \mathrm{ml}\end{array}$} & \multirow[b]{2}{*}{$\begin{array}{c}\text { Sensible a } \\
\text { ambas }\end{array}$} & \multicolumn{2}{|c|}{ Resistente a } & \multirow[b]{2}{*}{ Totales } \\
\hline & & & $\begin{array}{l}\text { Estreptomicina } \\
\text { (Disco } 10 \mathrm{ug} \text { ) }\end{array}$ & $\begin{array}{l}\text { Sulfafurazol } \\
\text { (Disco } 100 \text { ug) }\end{array}$ & \\
\hline & 0,03 & 25 & 2 & 2 & 29 \\
\hline & 0,06 & 4 & 1 & 3 & 8 \\
\hline & 0,15 & 3 & 7 & - & 10 \\
\hline & 0,3 & 0 & 5 & - & 5 \\
\hline & 0,6 & 1 & 1 & - & 2 \\
\hline & 1,2 & 0 & 2 & - & 2 \\
\hline & Totales & 33 & 18 & 5 & 56 \\
\hline
\end{tabular}

* Todas las cepas examinadas eran sensibles a los siguientes agentes antibacterianos con las dosis indicadas:

Sulfametoxazol/trimetoprim $\quad \ldots \quad \ldots \quad \ldots \quad 25$ ug

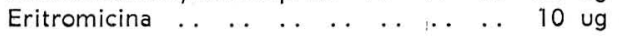

$\begin{array}{ccccccccccc}\text { Canamicina } & \ldots & \ldots & \ldots & \ldots & \ldots & \ldots & \ldots & 30 & \mathrm{ug}\end{array}$

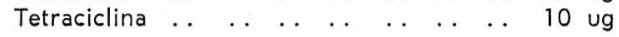


TABLA 2

RESULTADOS DEL TRATAMIENTO CON SULFAMETOXAZOL/TRIMETOPRIM EN 58 PACIENTES QUE VOLVIERON A CONSULTA DESPUES DE LA VISITA INICIAL

(Las cifras entre paréntesis indican las que todavía están sujetas a asistencia)

\begin{tabular}{|c|c|c|c|c|}
\hline \multirow[b]{2}{*}{$\begin{array}{l}\text { Período de vigilancia } \\
\text { (días) }\end{array}$} & \multirow[b]{2}{*}{$\begin{array}{l}\text { Número } \\
\text { controlado }\end{array}$} & \multicolumn{3}{|c|}{ Resultados en la última asistencia } \\
\hline & & Satisfactoria & Reinfección & $\begin{array}{c}\text { Fallo } \\
\text { Tratamiento }\end{array}$ \\
\hline 3,4 ó 5 & 58 & 5 & - & 1 \\
\hline 8 & 52 & $5^{*}(3)$ & - & - \\
\hline 15 & 47 & $5(4)$ & 1 & - \\
\hline 22 & 41 & $10(6)$ & 1 & - \\
\hline 29 & 30 & 30 & - & - \\
\hline Totales & 58 & 55 & 2 & 1 \\
\hline
\end{tabular}

* Una paciente, descartada después de recibir penicilina por otra causa.

En la Tabla 1 se recopilan los hallazgos bacteriológicos de 56 de las cepas de $\mathbf{N}$. gonorrhoea aisladas. En 9 casos, dejaron de desarrollarse cultivos o subcultivos. La sensibilidad a la penicilina se estimó por el método de la dilución en tubos y la sensibilidad o resistencia a otros agentes antibacterianos, por el del disco, con la dosis indicada. Unicamente se encontró resistencia a la estreptomicina y al sulfafurazol. Ninguna fue resistente al sulfametoxazol-trimetoprim, eritromicina, cana- micina o tetraciclina, lo cual concuerda con las cepas de N. gonorrhoea normalmente aisladas en Glasgow.

La Tabla 2 contiene los resultados del tratamiento de las 58 pacientes que volvieron después de la visita inicial. Unicamente una $(1,5 \%)$ de las 65 dejó de responder a la asociación sulfametoxazol / trimetoprim prescrita, otra tuvo 2 reinfecciones, al principio, el día 15, y después, el día 22, tras el nuevo tratamiento. Nin-

TABLA 3

PROPORCIONES DE FALLOS EN EL TRATAMIENTO DE LA BLENORRAGIA FEMENINA

\begin{tabular}{|c|c|c|c|c|}
\hline Autores & Fecha & Medicamentos & Dosis & $\begin{array}{l}\text { Porcentaje } \\
\text { de fallos } \\
(\%)\end{array}$ \\
\hline Lucas y cols. & 1967 & $\begin{array}{l}\text { I.M., penicilina con procaína } G \text { (acuosa) } \\
\text { penicilina con procaína } G \text { (oleosa) }\end{array}$ & $\begin{array}{l}2,4 \text { M.U. } \\
2,4 \text { M.U. }\end{array}$ & 10,7 \\
\hline " & $"$ & I.M., penicilina con procaína G (acuosa) & 4,8 M.U. & 14,4 \\
\hline " & " & I.M., peniciina con procaína G (acuosa) & 2,4 M.U. & 17,9 \\
\hline$"$ & $"$ & I.M., espectinomicina & $4,0 \mathrm{~g}$ & 18,0 \\
\hline McLone „y cols. & 1968 & Oral, tetraciclina $\mathrm{HCl}$, dosis sencilla & $1,5 \mathrm{~g}$ & 13 \\
\hline Jouhar y Fowler & & I.M., cefaloridina & $2,0 \mathrm{~g}$ & 15 \\
\hline Jouhar y Fowler & 1968 & I.M., cefaloridina & $2,0 \mathrm{~g}$ & 7,1 \\
\hline Hooton y Nicol & & I.M., cefaloridina $(2 \times 1,0 \mathrm{~g})$ & $2,0 \mathrm{~g}$ & 5,7 \\
\hline $\begin{array}{l}\text { Hooton y Nicol } \\
\text { McGill y cols. }\end{array}$ & 1967 & I.M., canamicina & $2,0 \mathrm{~g}$ & 3,6 \\
\hline $\begin{array}{l}\text { McGill y cols. } \\
\text { Estudio actual }\end{array}$ & 1969 & I.M., canamicina & $2,0 \mathrm{~g}$ & 5 \\
\hline Estudio actual & & Sulfametoxazol/trimetoprim oral & & 15 \\
\hline
\end{tabular}


guna de las que no respondieron eran consideradas fuentes de blenorragia y los maridos de más de la mitad se mantuvieron bajo vigilancia, sin registrarse recidivas. Se prescindió de una paciente que había recibido penicilina con motivo de una afección a la garganta. Treinta y cuatro de las 64 pacientes sufrían infección concomitante por tricomonas y una de infección-por moniliasis, ninguna de las cuales fue afectada por sulfametoxazol/trimetoprim.

La encuesta rutinaria demostró que la presentación del medicamento era aceptable y que ninguna paciente había encontrado dificultades para ingerir las grageas.

Dos pacientes informaron sobre posibles reacciones al tratamiento: una, se quejaba de tumefacción facial al 20. día, que desapareció antes de terminado el tratamiento y en la otra se observó un exantema al 7\% día, 2 días después de terminado el tratamiento, que su médico general diagnosticó como rubeola. Una tercera paciente sufrió hepatitis infecciosa al 7 : día.

Los resultados hematológicos no revelan discrasias sanguíneas. Las hemoglobinas iniciales de menos de $13 \mathrm{~g} \%$ tendían a aumentar, mientras que las superiores, no. Una cifra inicial de 8.000 leucocitos tendió a bajar; las inferiores a 6.000 no.

En la Tabla 3 se comparan las proporciones de fallos entre los tratamientos de la blenorragia femenina con sulfametoxazol-trimetoprim y con otros métodos. El primero parece ser el mejor, cuando se administra durante 5 días y por vía oral.

\section{Comentario}

Parece ser que la asociación de sulfametoxazol y trimetoprim resul- ta muy eficaz en el tratamiento de la blenorragia femenina, mucho más difícil de curar que la masculina.

Ninguna de las cepas aisladas inicialmente fue resistente a este medicamento, aunque el caso que dejó de responder acusaba una sensibilidad disminuída a la asociación en el cultivo positivo tomado el día 5 en que se supuso el fallo, a causa de la persistencia de $\mathbf{N}$. gonorrhosa en frotis $y$ cultivos. Los hallazgos iniciales fueron los siguientes: penicilina $G$, $\mathrm{CIM}, 0,03 \mathrm{ug} / \mathrm{ml}$, resistente al sulfafurazol únicamente, y en el $5^{\circ}$ día, penicilina $\mathrm{G}, \mathrm{CIM}, 0,03 \mathrm{ug} / \mathrm{ml}$ resistente al sulfafurazol y con disminución de la sensibilidad a la combinación de sulfametoxazol/trimetoprim. La zona de inhibición había bajado de 30 a $18 \mathrm{~mm}$. de diámetro.

Una paciente tuvo 2 reinfecciones, la primera en relación con un cambio en el antibiograma de penicilina $G, C I M 0,6 \mathrm{ug} / \mathrm{ml}$, sensible a todos los demás medicamentos, a la penicilina $G, C I M, 0,6 \mathrm{ug} / \mathrm{ml}$, resistente a la estreptomicina únicamente en el $15^{\circ}$ día, y la segunda, al $22^{\circ}$. día del nuevo tratamiento, con sensibilidades similares; pero después de un cierto número de exposiciones a la reinfección.

Normalmente, es baja la incidencia de cepas de $\mathbf{N}$. gonorrhoea resistentes in vitro a las sulfamidas. Ciertamente, contamos con nuestros hallazgos de Glasgow de los últimos 4 años, que parecen confirmar la disminución de la resistencia de la $\mathbf{N}$. gonorrhoea a la sulfadimidina in vitro, comprobada por Hirsch y Finland (1960), los cuales compararon las cepas aisladas en 1949, 1954 y 1959, encontrando una progresiva disminución de la sensibilidad durante dicho período. Sin embargo, debemos controlar la sensibilidad a es- 
te nuevo medicamento durante los próximos años para tener la seguridad de que no se va a desarrollar una resistencia. Normalmente, la asociación sulfametoxazol - trimetoprim registra una proporción de curaciones más elevada que cualquier otro medicamento, aunque ha de ser administrada por vía bucal durante un período de 5 días. Según nuestro estudio, no produce reacciones ni discrasias sanguíneas.

Como el medicamento se administra por vía oral, únicamente debe prescribirse a pacientes de las que se espera observen las instrucciones. Como la mayoría de nuestras pacientes no ofrecen garantía a este respecto, se espera con impaciencia un medicamento que se pueda utilizar en inyecciones intramusculares.

\section{AGRADECIMIENTO}

Deseamos dar las gracias a nuestros colegas en la Clínica por su cooperación, Dres. T. F. Elías-Jones y M. Laidlaw del Laboratorio Municipal de Glasgow, por sus trabajos bacteriológicos y hematológicos, así como al Dr. H. Holgate y a Roche Products Ltd. por su ayuda y por el suministro de Bactrim.

\section{BIBLIOGRAFIA}

CSONKA, G. W. y KNIGHT, G. J. (1967) Therapeutic trial of trimethoprim as a potentiator of sulphonamides in gonorrhoea. Brit. J. vener. Dis. 43, 161.
DARRELL, J. H., GARROD, L. P. y WATERWORTH, P. M. (1968). Trimethoprim; laboratory and clinical studies. J. Clin.

Path. 21, 202.

HIRSCH, H. A. y FINLAND, M. (1960). Susceptibility of gonococci to antibiotics and sulfadiazine. Estudio de cepas aisladas en el Hospital Municipal de Boston de casos de uretritis gonorreica aguda en hombres, de agosto de 1958 a febrero de 1959.

Amer. J. med. Sci. 239, 41.

HOOTON, W. F. y NICOL, C. S. (1967). Kanamicyn in the treatment of gonorrhoea in females. Postgrad. med. J. 43, suplemento (mayo), pág. 68.

JOUHAR, A. J. Y FOWLER, W. (1968). Cephaloridine in gonorrhoea in females. Brit. J. vener. Dis. 44, 223.

LUCAS, J. B., PRICE, E. V., THAYER, J. D. Y SCHROETER, A. (1967). Diagnosis and treatment of gonorhoea in the female. New Engl. J. med. 276, 1454.

MCLONE, D. G., BILLINGS, T. E., HARDEGREE, W. E. y HACKNEY, J. F. (1968). Gonorrhoea in females treated with one oral dose of tetracycline. Brit. J. vener. Dis. 44, 218.

MCLONE, D. G., SCOTTI, A. T., MACKEY, D. M. Y HACKNEY, J. F. (1968). Cephaloridine treatment of gonorrhoea in the female. Brit. J. vener. Dis. 44, 220.

MCGILL, M. I., MOFFETT, M., MASTERSON, G. y SCHOFIELD, C. B. S. (1969). Kamamycin in the treatment of gonorrhoea in the femaie. Scot. med. J. 14, 176.

ROTH, B., FALCO, E. A., HITCHINGS, G. H. y BUSHBY, S. R. M. (1962). 5-Benzyl-2,4diaminopyrimidines as antibacterial agents. I. Synthesis and antibacterial activity in vitro. J. med. pharm. Chem. 5, 1103. 